\title{
EL DERECHO NATURAL Y LA INCONSTITUCIONALIDAD DE LOS DELITOS DE LESA HUMANIDAD: BASES PARA UNA APROXIMACIÓN AL DEBER DE OBEDIENCIA AL DERECHO EN EL CASO "SIMÓN"
}

\author{
Natural LaW and the \\ Constitutionality of Crimes against \\ Humanity: Basis for an Approach to \\ the Obligation to Obey the Law in \\ the Simón CASE
}

O DiREITO Natural E A INCONSTITUCIONALIDADE DOS DELITOS CONTRA A HUMANIDADE: BASES PARA UMA APROXIMAÇÃO AO DEVER DE OBEDIÊNCIA AO DIREITO NO CASO "SIMÓN" LUCIANO DAMIAN LAISE*

Universidad de Buenos Aires (UBA). Argentina. llai-se@ius.austral.edu.ar. El autor agradece las sugerencias y observaciones de los evaluadores anónimos, ya que permitieron incrementar la calidad final de este artículo.

RECIBIDO: O6 DE MARZO DE 2015. ENVÍO A PARES: O9 DE MARZO DE 2015 APROBADO POR PARES: O2 DE JUNIO DE 2015. ACEPTADO: O3 DE JUNIO DE 2015

DOI: $10.5294 / D I K A .2015 .24 .2 .6$

PARA CITAR ESTE ARTí́CULO / TO REFERENCE THIS ARTICLE / PARA CITAR ESTE ARTIGO LAISE, LUCIANO DAMIAN, "EL DERECHO NATURAL Y LA INCONSTITUCIONALIDAD DE LOS DELITOS DE LESA HUMANIDAD: BASES PARA UNA APROXIMACIÓN AL DEBER DE OBEDIENCIA AL DERECHO EN EL CASO ‘SIMÓN'”, EN DIKAION 24-2 (2015), PP. 336-352. DOI: 10.5294/DIKA.2015.24.2.6 


\section{RESUMEN}

En el presente artículo se examina el caso "Simón", en el que la Corte Suprema de Justicia de la Nación Argentina declaró la invalidez constitucional de las leyes 23.492 y 23.521 de punto final y de obediencia debida. Tales leyes establecian la renuncia a la persecución penal de delitos de lesa humanidad, en pos de una convivencia social pacífica apoyada en el perdón de hechos de esa naturaleza. La perspectiva que se adoptará en este trabajo está centrada en defender la idea de que lo resuelto por la Corte argentina descansa en una visión transpositivista del derecho. Más en concreto, en una noción de obediencia al derecho que resultaria compatible con una de las tesis centrales de la tradición iusnaturalista.

\section{PALABRAS CLAVE}

Derecho natural; deber de obediencia al derecho; Corte Suprema de Justicia de la Nación Argentina; delitos de lesa humanidad. 


\begin{abstract}
The article looks at the "Simon" case in which the Supreme Court of Argentina declared the Full Stop Law (23.492) and the Law of Due Obedience (23.521) unconstitutional and void. These laws waived prosecution of crimes against humanity, supposedly for the sake of peaceful social coexistence. The perspective adopted in this article focuses on defending the notion that the decision of the Argentine court rests on a trans-positivist vision of the law. More specifically, it is based on a concept of obedience of the law that would be compatible with one of the central hypotheses of the iusnaturalist tradition.
\end{abstract}

\title{
KEYWORDS
}

Natural right; duty to obey the law; Supreme Court of Argentina; crimes against humanity. 


\section{RESUMO}

No presente artigo, examina-se o caso "Simón", no qual a Suprema Corte de Justiça da Nação Argentina declarou a invalidade constitucional das leis 23.492 e 23.521 de ponto final e de obediência. Tais leis estabeleciam a renúncia à persecução penal de delitos de lesa humanidade em prol de uma convivência social pacífica apoiada no perdão de atos dessa natureza. A perspectiva que se adota neste trabalho está centrada em defender a ideia de que o resolvido pela Corte argentina repousa numa visão transpositivista do direito. Mais em concreto, numa noção de obediência ao direito que resultaria incompativel com uma das teses centrais da tradição iusnaturalista.

\section{PALAVRAS-CHAVE}

Direito natural; dever de obediência ao direito; Suprema Corte de Justiça da Nação Argentina; delitos de lesa humanidade. 


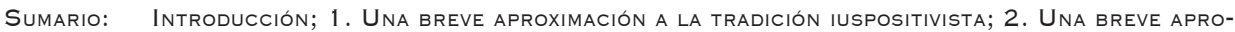
XIMACIÓN A LA TRAdición IUSNATURALISTA; 3. El DERECHO NATURAL COMO Última RATIO DE LA OBEdiencia a las normas del ordenamiento jurídico; 3.1. Algunas referencias explícitas al Concepto de derecho natural; 3.2. Algunas Referencias implí́citas al concepto de derecho NATURAL; 4. A modo de CONClusión; Bibliografía.

\section{INTRODUCCIÓN}

Este artículo introduce al lector en los principales aspectos del concepto de derecho natural que presupone una sentencia de la Corte Suprema de Justicia de la Nación Argentina, de suma relevancia institucional. Me refiero específicamente al caso "Simón". ${ }^{1}$ Se trata de un leading case, de central importancia en la jurisprudencia argentina, sobre la constitucionalidad del perdón o amnistía de los "delitos de lesa humanidad" cometidos en la última dictadura cívico-militar. Grosso modo, en el citado precedente se declaró la invalidez constitucional de las leyes 23.492 y 23.521 de punto final y de obediencia debida, cuya finalidad se dirigia a la renuncia a la persecución penal de delitos de lesa humanidad, en pos de una convivencia social pacífica apoyada en el perdón de hechos de esa naturaleza.

No pretenderé partir de ese fallo para llegar a agotar exhaustivamente la infinita riqueza que presenta el tópico del derecho natural en relación con el perdón de tales delitos. Tampoco aspiro a brindar una respuesta definitiva a una cuestión iusfilosófica que ya carga con muchos siglos de historia detrás de sí. Vargas Guillén ha escrito que "los problemas filosóficos no tienen solución, sino historia". ${ }^{2}$ Quizá haya excepciones a esta última afirmación pero, a mi modo de ver, se aplica con toda la contundencia posible a la cuestión del derecho natural.

No aspiro en este trabajo a discutir la justicia o injusticia de la solución concreta a la que arribó el tribunal en el citado fallo. Existe una abundante bibliografia al respecto. ${ }^{3}$ Pero tampoco quisiera cometer la necedad de cuestionar la relevancia e interés teórico y práctico de lo último. Así, la principal contribución que pro-

1 CSJN, “Simón, Julio H. y otros s/privación ilegitima de la libertad”, Fallos: 328:2056 (en adelante: "Simón”). Aclaro que no haré referencia a la página correspondiente de la colección de fallos de la Corte Suprema de Justicia de la Nación. Para facilitar el cotejo de las referencias con el texto original de la sentencia he considerado más útil citar por medio de una referencia al voto de cada juez, el número del considerando y, si correspondiera, el párrafo específico dentro del considerando en cuestión.

2 Cfr. Guillermo Vargas Gulllén, "Prólogo", en Giovanni Reale y Darío Antíseri, Historia de la Filosofia I: Filosofia Pagana Antigua, Bogotá, Sociedad San Pablo, trad. J. Gómez, 2007, p. 7. En un sentido similar, Pedro SERnA, Filosofia del derecho y paradigmas epistemológicos: de la crisis del positivismo a las teorías de la argumentación jurídica y sus problemas, México D. F., Porrúa, 2006, pp. 1-2.

3 Ver, entre otros, Renato RABBi-BALd CABAnILlas, "La causa 'Simón' de la Corte Suprema argentina. Un análisis desde la filosofia del derecho, en AA. VV., Delitos de lesa humanidad. Reflexiones acerca de la jurisprudencia de la CSJN, Ediar, Buenos Aires, 2009, pp. 101-114. Santiago LEGARRE, "Crimes against Humanity, Reasonableness and the Law: the Simon Case in the Supreme Court of Argentina”, en Chinese Journal of International Law 5/2 (2006), pp. 723-732. Christine A. E. BAKKER, "Full Stop to Amnesty in Argentina: the Simón Case", en Journal of International Criminal Justice 3 (2005), pp. 1106-1120. Rodolfo L. VIGo, "Consideraciones iusfilosóficas sobre la sentencia en la causa "Simón”, en La Ley 2005-D, 1245. Gregorio BADENI, "El caso ‘Simón’ y la supremacía constitucional”, en La Ley 2005-D, 639. 
porcionaré al estudio del caso "Simón" radica en poner de relieve que cualquier valoración, a favor o en contra de lo resuelto por la Corte Suprema de Justicia de la Nación (en adelante, CSJN), presupone necesariamente una determinada concepción iusfilosófica que descansa, en última instancia, en un concepto transpositivista del derecho. En tal sentido, me valdré de la distinción entre teorías iuspositivistas y transpositivistas. Bajo esta última categoría se encontrarían "todas las teorías que aceptan la existencia de al menos un principio jurídico no positivo". Dentro del transpositivismo cabría subdividir entre aquellas teorías que remiten a algún tipo de conocimiento de las cosas humanas, que Massini denomina iusnaturalistas en sentido estricto, y aquellos otros enfoques teóricos que no efectúan tal remisión y se limitan a proponer algún modo de construcción racional de los principios prácticos, que suelen denominar genéricamente constructivistas. ${ }^{4}$ En este orden de ideas, en este trabajo defenderé la tesis de que lo resuelto en el caso "Simón" supone un abierto rechazo a un concepto del derecho anclado en la tradición iuspositivista. Aun más, el citado fallo implica la asunción de un peculiar concepto de derecho de tipo transpositivista, en tanto presupone o implica una noción de obediencia del derecho positivo que resultaría compatible con la tradición iusnaturalista.

La aproximación escogida en este trabajo se justifica en el entendimiento de que la filosofía del derecho ejerce una función valorativa y crítica de la realidad jurídica tal como se le presenta a los operadores del derecho. ${ }^{5}$ En efecto, solo a la luz de una aproximación iusfilosófica sería posible evaluar las leyes de "punto final" y "obediencia debida" según su corrección e incorrección, justicia e injusticia, de acuerdo a su correspondencia con las exigencias básicas del ser humano y de la vida en sociedad. ${ }^{6}$ Así, después de echar luz sobre algunos de los presupuestos filosóficos sobre los cuales se apoya el fallo $-\mathrm{y}$ en particular en la medida en que se comprenda cuál es el concepto de derecho natural que presupone-, se podrá estar en condiciones adecuadas para valorar cabalmente la resolución adoptada por la Corte Suprema de Justicia de la Nación ante el caso "Simón”. Dicho de otro modo, con este artículo pretendo sentar las bases teóricas sobre la cuales habría de formularse una valoración que defienda o critique el núcleo decisorio del caso, a saber: la inconstitucionalidad de las leyes de amnistía.

Soy consciente de que cualquier intento de agrupar las respuestas que se han dado a la cuestión del derecho natural a lo largo de la historia de las ideas constituye un esfuerzo teórico demasiado ambicioso para un trabajo de estas características. Sin pretensiones de exhaustividad, siendo consciente que en cada tradición filosófica existen múltiples corrientes y propuestas teóricas, ${ }^{7}$ me permitiré simplificar las

4 Cfr. Carlos Ignacio Massini Correas, Constructivismo ético y justicia procedimental en John Rawls, México D.F., UNAM, 2004, p. 10.

5 Cfr. Eduardo Martín Quintana, Notas sobre el derecho en el iusnaturalismo, Buenos Aires, Educa, 2008, p. 141

7 Cfr. Renato RabBi-Baldi Cabanillas, Teoría del derecho, 3 edición, Buenos Aires, Abaco, 2013, p. 114. 
posiciones teóricas en dos líneas explicativas. Por un lado, me basaré en la caracterización de las tesis nucleares del iuspositivismo de Norberto Bobbio, quien ha efectuado una célebre descripción de las afirmaciones fundamentales de las teorias que se incardinan en la tradición iuspositivista. La elección de la descripción del profesor turinés se podría justificar en el hecho de que suele ser aceptada por los mismos autores que se autoproclaman positivistas. ${ }^{8}$ Por el otro, presentaré las tesis centrales de la tradición iusnaturalista a través de un diálogo con la caracterización de la concepción iuspositivista que presenta el citado profesor italiano. A partir de tales respuestas, centrándome en la cuestión de la obediencia al derecho, pasaré a examinar el concepto de derecho natural que asume la CSJN en el caso "Simón". Luego, mostraré algunas alusiones explícitas e implícitas a tal concepto de derecho natural como fundamento del deber de desobediencia a las normas jurídicas que implicaron crimenes de lesa humanidad en el citado fallo. Finalmente, brindaré una conclusión.

\section{UNA BREVE APROXIMACIÓN A LA TRADICIÓN POSITIVISTA}

Las teorias que se incardinan dentro de la tradición iuspositivista, entre otras cuestiones, suelen rechazar la conexión necesaria entre derecho natural y derecho positivo, en diferentes medidas y apelando a variados argumentos, según de la teoría particular de la que se trate. La última tradición filosófica engloba, a grandes rasgos y de modo esquemático, a diferentes propuestas teóricas que, según Bobbio, suelen caracterizarse por defender alguna o algunas de las siguientes tesis: i) un peculiar modo de acercarse al estudio del derecho; ii) una determinada teoría del derecho; y iii) una particular ideologia sobre la relación entre derecho y justicia. ${ }^{9}$

En relación con la primera de las tesis positivistas, Bobbio sostiene que el positivismo jurídico supone una particular delimitación del objeto de estudio que se circunscribe al "derecho tal como es" y no al "derecho como debería ser". De esta manera, al iuspositivismo solo le interesaría describir el derecho tal como se presenta en la vida de los operadores jurídicos, sin considerar su correspondencia con el derecho ideal o con el derecho como "debería ser" ${ }^{10}$. En tal sentido, como afirma Kelsen, a la ciencia jurídica no le interesa la pregunta por cómo debería

8 Para un ejemplo que muestra que las tres tesis que enuncia Bobbio resultan un lugar común o punto de partida del positivismo jurídico contemporánea, cfr. Carlos BAYÓN MoHÍno, "El contenido mínimo del positivismo jurídico", en Horizontes de la filosofia del derecho: homenaje a Luis García San Miguel Virgilio ZAPATERo Gómez (coord.), vol. 2, 2002, pp. 33-54. Para una exhaustiva valoración crítica de la caracterización de las tesis nucleares del positivismo jurídico que realiza Bobbio desde un paradigma filosófico no positivista, Pedro SERna, "Sobre las respuestas al positivismo jurídico”, en Persona y Derecho 37 (1997), pp. 282-283. Este último autor español ha analizado más detalladamente la obra iusfilosófica de Bobbio en, Positivismo conceptual y fundamentación de los derechos humanos, Pamplona, Eunsa, 1990, pp. 17-27; pp. 31-62; pp. 137-164.

9 Cfr. Norberto BoвBio, El problema del positivismo jurídico, , 5 edición, México D. F., Fontamara, trad. E. Garzón Valdés, 1997, pp. 39-40.

34210 Ibid., p. 41. En la hora presente, entre quienes defienden la mentada separación entre los "juicios de valor" y "prescripciones normativas" se destaca en la filosofia jurídica continental, entre otros, Riccardo Guastini. Manuel Atienza, "Entrevista a Riccardo Guastini”, en Doxa: Cuadernos de Filosofia del Derecho 27 (2004), p. 460. 
ser el derecho sino exclusivamente la descripción del derecho tal como es o, lo que para él es lo mismo, el derecho positivo. ${ }^{11}$ La cuestión en torno a cómo debería ser el derecho, a lo sumo, podría caer dentro del objeto de estudio de la política legislativa. ${ }^{12}$ Por tanto, de esta primera tesis se puede concluir que para el positivismo jurídico el conocimiento científico sobre el derecho está separado de la moral o de la justicia en virtud de la cual se podría calificar a las normas jurídicas positivas. ${ }^{13}$ Respecto de la segunda tesis - el derecho como teoría-, Bobbio afirma que el positivismo jurídico mantiene una concepción particular del derecho que se basa en una aproximación no valorativa o descriptiva. ${ }^{14}$ Ese modo de acercarse teóricamente al derecho, grosso modo, se caracteriza por mantener que el fenómeno jurídico se encuentra unido a la formación de un poder soberano capaz de ejercitar la coacción sobre los ciudadanos: el Estado. ${ }^{15}$ En tal orden de ideas, Kelsen mantiene que puede haber normas que prescriban cómo se deben comportar las personas - v. gr., las normas morales de una comunidad religiosa- Sin embargo, tales normas solo podrian ser calificadas como jurídicas en tanto dimanen de los órganos estatales competentes que establecen consecuencias jurídicas ante el incumplimiento de lo normado; vale decir, consecuencias que se apoyan en el uso o en la amenaza del uso de la fuerza pública. ${ }^{16}$ En sintesis, como afirmaba Kelsen, "la ciencia jurídica solo puede describir lo que la autoridad jurídica prescribe". ${ }^{17}$ Dicho de otro modo, la ciencia del derecho solo se limita a explicar —en el sentido de "describir"- las prescripciones dictadas por quienes ejercen el gobierno del Estado, conforme a las atribuciones conferidas previamente por el propio derecho positivo.

Finalmente, siguiendo la caracterización de Bobbio, cabe mencionar la tesis del positivismo jurídico como ideología. Según esta última afirmación, el derecho positivo, por el mero hecho de existir, implica un valor encomiable, independientemente de su contenido material o conexión con el derecho tal como "debería ser". ${ }^{18}$ La atribución del valor encomiable al derecho positivo, para el citado profesor italiano, suele apoyarse en dos lineas argumentativas: i) el derecho positivo es justo por el solo hecho de ser "positivo"; vale decir, el derecho es justo por ser la emanación de una voluntad política dominante. Así, el criterio para evaluar su justicia equivale al criterio para juzgar la validez de las normas jurídicas. ${ }^{19}$ ii) $\mathrm{El}$ derecho, en tanto sistema de reglas impuestas por el poder que ejerce el monopolio de la fuerza en una determinada sociedad sirve, con su sola existencia, para la realización de fines sociales deseables tales como el orden, la paz y la seguridad

11 Cfr. Hans Kelsen, "The Pure Theory of Law: its Method and Fundamental Concepts", en The Law Quarterly Review 50 (1934), p. 477.

12 Cfr. BobBio, El problema del positivismo jurídico, op. cit., p. 43. Kelsen, "The Pure Theory of Law: its Method...”, op. cit., p. 477.

13 Cfr. Kelsen, "The Pure Theory of Law: its Method", op. cit., p. 482.

14 Cfr. Boвbio, El problema del positivismo jurídico, op. cit., p. 43.

15 Idem.

16 Cfr. Kelsen, "The Pure Theory of Law: its Method", pp. 485-486.

17 Hans Kelsen, "What is the Pure Theory of Law?", Tulane Law Review 34 (1960), p. 271 (traducción propia).

18 Cfr. BobBio, El problema del positivismo jurídico, op. cit., pp. 46-47.

19 Idem. 
jurídica. ${ }^{20}$ Ambas lineas confluyen, siempre según Bobbio, en la consecuencia de que las normas deben ser obedecidas por sí mismas y, por tanto, se podria hablar de que existe un deber moral de obedecerlas; esto es, la obligación interna o en conciencia de hacerlo. ${ }^{21}$

\section{UNA BREVE APROXIMACIÓN A LA TRADICIÓN IUSNATURALISTA}

La tradición iusnaturalista, más allá de las variadas y múltiples corrientes teóricas que se autoproclaman "iusnaturalistas", se caracteriza por diversas aproximaciones teóricas que, sin embargo, comparten un cierto "aire de familia" que se podría caracterizar, a grandes rasgos, por la defensa de una continuidad entre el derecho natural y el derecho positivo. Las afirmaciones centrales que se siguen de tal continuidad podrían ser presentas sintéticamente como respuestas a las tres tesis nucleares que señala Norberto Bobbio en su conocida caracterización del positivismo jurídico, cuyas notas más saliente fueron enunciadas en las páginas anteriores.

Más específicamente, se podría mencionar que el iusnaturalismo mantiene que no es deseable, ni posible, una aproximación no valorativa al derecho. No es deseable porque existe una profunda continuidad entre la ética o moral y el derecho. Lo último no pretende sugerir que el derecho equivale completamente a la moral, sino que el primero se podría caracterizar como la "medida mínima de lo ético" que posibilita la convivencia social; vale decir, no se pretende que todas las posibles cuestiones morales o éticas caigan bajo el ámbito del derecho, sino solamente aquellas de las que pueden abstenerse la mayoría y que, a la vez, dañan o pueden dañar seriamente a terceros. ${ }^{22}$ En otras palabras, de lo que se trata es de mantener la pretensión que caracterizó históricamente al derecho -y sobre todo a la ley- como instrumento que posibilita la paz social y la vida en común o, lo que es lo mismo, la vida humana en comunidad.

Asimismo, tampoco es posible excluir las valoraciones del mundo del derecho porque, como señala John Finnis, es imposible realizar descripciones sin antes haber efectuado elecciones metodológicas con base en criterios valorativos. ${ }^{23}$ De hecho, la opción por una perspectiva exclusivamente descriptivista, que se centra exclusivamente en el derecho tal como "es" —el derecho positivo- y no sobre como "debería

20 Idem.

21 Idem.

22 Vale mencionar que Tomás de Aquino mantenía que la ley positiva no debe proscribir todos los vicios de los que se abstiene una persona virtuosa sino solamente los más graves; aquellos de los que puede abstenerse la mayoría y que, sobre todo, hacen daño a los demás; sin cuya prohibición la sociedad no podría subsistir. Cfr. TomÁs DE Aguino, Suma Teológica, I-II, q. 96, a. 2 (se cita la edición dirigida por los Regentes de Estudios de las Provincias Dominicanas en España, B. A. C., Madrid, 1989).

34423 Cfr. John Finnis, Natural Law and Natural Rights, 2 edición, Oxford, Oxford University Press, 2011, pp. 16-18. (Existe versión en lengua castellana, Ley Natural y Derechos Naturales, trad. C. ORREGo, Buenos Aires, Abeledo-Perrot, 2000). 
ser" —el derecho natural—, tal como lo sostienen las versiones más estrictas del positivismo jurídico actual, presupone una elección y, por lo mismo, la valoración de una determinada metodología como la más apropiada para abordar al derecho como objeto de estudio. Por consiguiente, toda descripción científica que se autolimita al derecho positivo presupone necesariamente una valoración previa que considera encomiable una particular opción metodológica que consiste en excluir de la ciencia jurídica a todo aquel elemento que podría estar conectado con el conocimiento jurídico - v. gr., moral, política, economía, expectativas sociales, etc.—.

Respecto del derecho como teoría, se podria afirmar, en muy apretada sintesis, que el iusnaturalismo considera que el estudio del fenómeno jurídico no se limita exclusivamente a describir las normas jurídicas como las entiende el positivismo jurídico; vale decir, en tanto normas que se encuentran respaldadas por la coerción estatal. No obstante, lo último no equivale a negar la relevancia del derecho positivo. Aun más, John Finnis considera que el sistema jurídico positivo es el "caso central" del derecho; ${ }^{24}$ vale decir, el derecho positivo, según el entendimiento del citado profesor australiano, sería el núcleo fundamental del derecho. Por consiguiente, la centralidad del derecho positivo para el estudio del fenómeno jurídico sería perfectamente compatible con la tradición iusnaturalista. Sin embargo, la última afirmación exige un matiz que le permite diferenciarse del iuspositivismo. La centralidad del derecho positivo a la que Finnis alude, en última instancia, no se apoya exclusivamente en la mera coerción estatal que respalda a las normas jurídicas positivas sino en la justicia o, al menos, en la posibilidad de asegurar la justicia a través de tales normas jurídicas-positivas que dimanan del sistema jurídico. En consecuencia, la coerción es un valor subordinado e instrumental para la realización de la justicia que normalmente expresan las normas jurídicas positivas. Se podría sugerir, en linea con el planteamiento finniseano, que la centralidad del derecho positivo descansa en su carácter de medio o instrumento que posibilita la justicia, uno de los elementos - el otro es la paz social- constitutivos del bien común de toda comunidad politica. ${ }^{25}$

Finalmente, en relación con el derecho como ideología - una tesis que ya ni siquiera mantienen abiertamente la mayor parte de los iuspositivistas actuales-, salta a la vista que la tradición iusnaturalista rechaza esa afirmación. En efecto, resulta inaceptable para esta última tradición defender el deber moral de obedecer al derecho positivo, con total prescindencia de su contenido material; vale decir, no es compatible con el iusnaturalismo afirmar que se ha de obedecer a las normas jurídicas positivas sin realizar algún tipo de deliberación práctica acerca de la injusticia o justicia, corrección o incorrección, de las normas que integran el ordenamiento jurídico-positivo. Sin embargo, esto último exige algunos matices puesto que no se pretende significar que la concepción iusnaturalista sostiene que cualquier norma jurídica positiva que pudiera ser calificada como injusta debería

25 Cfr. QuintanA, Notas sobre el derecho en el iusnaturalismo, op. cit., p. 45. 
o podría ser inmediatamente desobedecida. ${ }^{26}$ Dicho de otro modo, de la injusticia de las leyes positivas no se sigue invariablemente un deber de desobediencia.

Así, siguiendo en este punto a Joaquín García-Huidobro y Carlos Ignacio Massini Correas, se podría distinguir principalmente entre dos situaciones que podrían darse respecto de la obligación de obedecer el derecho. Primero, cabría diferenciar las normas jurídicas que se desvian del bien común pero que, dadas ciertas circunstancias y para evitar un mal común aún más grave, se podria derivar un deber "colateral" de obedecer al derecho. ${ }^{27}$ En efecto, existen leyes de las que se deriva el deber moral de soportar, sobre uno mismo, un cierto grado de injusticia —el ejemplo paradigmático son las leyes tributarias que implican una presión fiscal inequitativa que recae sobre un contribuyente-, no porque la obediencia a esa norma injusta se considere valiosa en sí misma sino porque sería peor que se generalizara su desobediencia. Se podría decir que se trataría de un "mal menor"; esto es, no es que resultase encomiable la obediencia a tales normas sino que sería aun más grave que su desobediencia se extendiera a todo el cuerpo social.

En segundo lugar, cabría hacer referencia a aquellas normas que prescriben directamente la realización de un mal grave sobre un tercero; ${ }^{28}$ en cuyo extremo, citando a Tomás de Aquino, tales leyes "nunca es lícito cumplirlas" ${ }^{29}$ Cabe remarcar que en este último caso ya no se trataría de normas jurídicas que implican soportar sobre uno mismo una injusticia; antes bien, se estaría frente a normas que prescriben infligir un mal extremadamente grave e injusto sobre terceros. Lo último se podría ejemplificar con aquellas normas que prescribían a los guardianes del muro de Berlin el deber de tirar a matar a quienes lo cruzaran ilegalmente. ${ }^{30}$

26 Este matiz exige ser destacado porque a menudo los autores incardinados en la tradición iuspositivista mantienen, generalmente sin mayores precisiones, que para el iusnaturalismo toda "ley injusta no es ley". Cfr., por ejemplo, H. L. A. HART, The Concept of Law, 2 edition, Oxford, Clarendon Press, 1994, pp. 156-157. En un sentido similar, Kelsen afirmaba que para el iusnaturalismo "el derecho positivo es válido si, y solo si, la conducta prescripta por él resulta conforme a la naturaleza humana o de las cosas”. Hans Kelsen, "On the Basis of Legal Validity”, trad. S. L. Paulson, American Journal of Jurisprudence 26 (1981), p. 186 (la última traducción es del autor de este trabajo). Desde la tradición iusnaturalista se han desarrollado diversas respuestas a las citadas afirmaciones. En efecto, trabajos recientes han demostrado exhaustivamente que la tesis de "la ley injusta no es ley" no encuentra sustento textual o conceptual en las obras de los principales autores clásicos de la tradición iusnaturalista —v. gr., Tomás de Aquino y Agustín de Hipona-. Carlos Ignacio Massini Correas y Joaquín García-Huidobro, "Valoración e inclusión en el Derecho. La máxima "Lex injusta non est lex" y la iusfilosofía contemporánea”, en Juan CiAnciardo et al. VV., Razón juridica moral: estudios sobre la valoración ética en el derecho, México D. F., Porrúa, 2011, pp. 117-145.

27 Cfr. Massini Correas y García-Huidobro, "Valoración e inclusión en el Derecho", op. cit., p. 126.

28 Ibid., p. 127.

29 Cfr. Tomás de Aguino, Suma Teológica, I-II, q. 96, a. 4 c.

30 Existe una profusa bibliografia en la que se discute la sentencia del Tribunal Constitucional Federal de Alemania recaída en el caso de "los guardianes del muro". Para una visión panorámica sobre tal caso y sus presupuestos iusfilosóficos, se recomiendan especialmente los trabajos de R. Vigo, R. Alexy, J. Seoane y E. R. Sodero, recopilados en R. L. Vigo (ed.), La injusticia extrema no es derecho (De Radbruch a Alexy), Buenos Aires, Eudeba, 2004, passim. 


\section{El DERECHO NATURAL COMO ÚlTima RATIO DE LA OBEDIENCIA A LAS NORMAS DEL ORDENAMIENTO JURÍDICO}

La cuestión del derecho natural podría plantear múltiples y variadas aristas a problemas iusfilosóficos que ni siquiera se podrían enunciar superficialmente en estas páginas. Con todo, de tal elenco de cuestiones, me he permitido escoger la relativa al derecho natural como última ratio $^{31}$ en la cual se apoya el sistema jurídico. Tal opción se justifica en el contexto del presente artículo en el hecho de que el caso "Simón” pone de relieve la siguiente cuestión teórica: ¿cuáles son los criterios últimos que justifican el deber de obedecer a las normas que integran el sistema jurídico? ¿Tales criterios se ubican dentro o fuera del sistema jurídico? ¿O acaso existe una instancia justificatoria que esté fuera del sistema jurídico como el mentado concepto de "derecho natural" que podría fundamentar el deber de obediencia a las normas de tal sistema?

La respuesta a tales interrogantes representa una de las cuestiones conceptuales más significativas que cabe analizar a partir del caso "Simón". Es preciso aclarar que no siempre es posible identificar explícitamente la expresión "derecho natural" en esa sentencia judicial. No obstante, se puede apreciar que en diversas oportunidades la Corte Suprema de Justicia de la Nación se apoya conceptualmente en un núcleo de juridicidad que no es disponible por el legislador ${ }^{32}$. El citado tribunal argentino asume que la atribución de juridicidad a una ley del Congreso que prescribe la amnistía de delitos de lesa humanidad no depende solamente del hecho de que tal ley haya sido dictada en uso de atribuciones constitucionales. Vale aclarar que la Constitución Argentina autoriza al Congreso Nacional a "conceder amnistías generales". ${ }^{33}$ En otras palabras, la ley de amnistía dictada por el Congreso Nacional, según lo que ha establecido la CSJN, no pertenece al sistema jurídico por el solo hecho de haber sido sancionada de acuerdo con las facultades conferidas por una norma constitucional.

Así, lo resuelto en el fallo que nos ocupa se basa en dos modos de hacer referencia a un peculiar concepto de derecho natural como última ratio sobre la cual descansa la justificación del ordenamiento jurídico positivo. Por un lado, i) referencias explícitas; vale decir, alusiones directas al concepto de derecho natural en el cuerpo de la sentencia y, por el otro, ii) referencias implícitas o conceptuales; esto es, apelaciones a un concepto de derecho que presupone implícitamente la

31 Ratio es una palabra latina sumamente dificil de traducir al idioma español. Su equivalente en lengua castellana suele identificarse, sin más, a "razón". No obstante, el sentido con que se utilizará ratio en este trabajo se remonta, al menos, hasta la Edad Media y más bien pretende significar "fundamento inteligible de una cosa". Cfr. Silvia Magnavacca, Léxico técnico de filosofia medieval, Buenos Aires, Miño y Dávila, 2005, p. 590.

32 Cfr. "Simón”, voto del juez Petracchi, consid. 23 , párrafo 2 .

33 Cfr. Constitución de la Nación Argentina, art. 75, inc. 20. 
necesidad de recurrir a una instancia justificatoria de la obediencia al derecho positivo que no descansa, a su vez, en otras normas jurídicas.

A continuación brindaré las principales referencias al concepto de derecho natural que se pueden detectar en el caso "Simón". El objetivo específico del próximo apartado tan solo pretende ilustrar cómo la cuestión relativa al derecho natural atraviesa el núcleo central de la decisión adoptada por la Corte Suprema. Así, mantendré la tesis de que la resolución de la Corte Suprema necesaria o inevitablemente prescinde de las tesis nucleares de una concepción positivista del derecho y, por ende, se apoya en lineamientos teóricos de tipo transpositivistas. Más en concreto, se analizará en qué medida la decisión de la Corte presupone una tesis de la obediencia al derecho compatible con la tradición iusnaturalista. Esto último no implica abrir ningún tipo de juicio acerca de si la Corte Suprema, ni siquiera en el caso bajo examen, asume coherentemente el resto de las tesis iusnaturalistas. Lo que sí se pretenderá mostrar es que las alusiones que hace la Corte en "Simón" al concepto de derecho natural guardan estrechas similitudes con el deber de desobedecer normas que prescriben la comisión de actos gravemente injustos sobre terceros, de un modo semejante a la caracterización de una de las tesis de la tradición iusnaturalistas expuesta más arriba. ${ }^{34}$

\subsection{Algunas referencias explícitas al concepto de derecho natural}

En relación con las referencias explícitas al "derecho natural", cabe mencionar las alusiones a tal concepto en el voto del juez Lorenzetti. Más en concreto, el citado magistrado afirma que en las diferentes "versiones del derecho natural o de derecho positivo existian cosas que no podían olvidarse y, por lo mismo, tampoco era susceptibles de ser perdonadas”. En tal sentido, Lorenzetti recuerda que ya desde uno de los primeros ejemplos históricos de amnistía; es decir, el decreto de perdón a la dictadura de los treinta tiranos de la antigua Atenas, se mantenía que no cualquier hecho podía encuadrarse dentro de tal clase de decretos. ${ }^{35}$ Con otras palabras, el ejemplo histórico de la citada dictadura ateniense muestra que no todo los crímenes pueden ser perdonados mediante una amnistia.

Otra de las más interesantes referencias explícitas al concepto de derecho natural en la argumentación que despliega la Corte se puede apreciar también en el voto del juez Zaffaroni. El citado jurista mantiene que la "invocación de un derecho supralegal para desconocer limites de legalidad siempre es peligrosa, pues todo depende de quién establezca lo que es o se pretende natural. Como es sabido, no hay una única teoría acerca del derecho natural, sino muchas”. En efecto, Zaffaroni simplifica las posiciones - algo completamente aceptable en el contexto de una sentencia judicial- y advierte que: "hay un derecho natural de raíz escolástica, otros de claro origen contractualista liberal y absolutista, pero también hubo

34 Cfr. Supra, apartado 3.

35 Cfr. "Simón”, voto del juez Lorenzetti, consid. 23, párrafo 1 .

DÍKAION - ISSN 0120-8942 
derechos naturales — con ese u otro nombre - autoritarios y totalitarios, abiertamente irracionales". ${ }^{36}$

Respecto del contexto en el cual se desplegaron los hechos sobre los que recae el caso "Simón", Zaffaroni advierte que las acciones contra el terrorismo emprendidas en nombre de la seguridad nacional también se justificaban implícitamente en un derecho supralegal. ${ }^{37}$ Sin embargo, el citado magistrado también reconoce que después de la Segunda Guerra Mundial surgió un influyente movimiento teórico de resurgimiento del iusnaturalismo que en Alemania sentó las bases para juzgar las atrocidades cometidas por los criminales nazis. En tal sentido, según indica el propio Zaffaroni, varias sentencias del Tribunal Constitucional de Alemania hicieron eco de las contribuciones teóricas de ese movimiento; en particular de la fórmula de Radbruch a la que se refiere directamente en el voto particular del citado magistrado. En concreto, Zaffaroni, siguiendo al citado autor alemán, sostiene que el derecho positivo debe ceder ante la justicia, "salvo que el conflicto entre la ley positiva y la justicia alcance una medida tan intolerable que la ley, como 'derecho injusto', ceda ante la justicia”. ${ }^{38}$

\subsection{Algunas referencias implícitas al concepto de derecho natural}

En el voto del juez Maqueda se puede detectar una referencia implícita al concepto de derecho natural que, a primera vista, pareciera configurar una contradicción. En efecto, el citado magistrado afirma que el reconocimiento de derechos preexistentes de las personas, entre ellos, el derecho a no ser objeto de persecuciones por el Estado, deriva en una protección universal de los derechos humanos que no descansa en una concepción iuspositivista o iusnaturalista del derecho. ${ }^{39}$

Las palabras del citado juez suponen que el ordenamiento jurídico positivo puede ser evaluado en su justicia o injusticia desde parámetros que no se desprenden del propio ordenamiento o sistema jurídico. Con otras palabras, el criterio último para justificar la obediencia de las normas jurídicas positivas se encuentra por fuera del derecho positivo. Esto último desborda a una concepción positivista del derecho y, en efecto, supone apelar a un fundamento último del sistema jurídico que no es meramente creado o positivizado sino descubierto o reconocido por la razón práctica; es decir, por el uso de la razón humana en orden a decidir lo que se debería actuar y resolver. ${ }^{40}$

Otra de las referencias implícitas al concepto de derecho natural se puede apreciar en las múltiples alusiones que se hacen a lo largo del fallo al "derecho de gentes"

36 Cfr. "Simón", voto del juez Zaffaroni, consid. 25, párrafo 1.

37 Ibid., párrafo 2 .

38 Ibid., párrafo 4 .

39 Cfr. "Simón", voto del juez Maqueda, consid. 33-34.

40 "Practical thought is thinking about what (one ought) to do. Practical reasonableness is reasonableness in deciding, in adopting commitments, in choosing and executing projects, and in general in acting”. Cfr. FinNis, Natural Law and Natural Rights, op. cit., p. 12. 
(ius gentium), particularmente en el voto del juez Maqueda. Este último concepto, en efecto, se caracteriza en diversos pasajes como un sistema de principios generales del derecho y de la justicia que implicaba una suerte de moralidad básica que vinculaba a las conductas de los Estados entre sí pero también con relación a sus habitantes. De manera que el derecho de gentes suponia elementos obligatorios que no podian ser violados por la legislación positiva. ${ }^{41}$ Más aún, tales elementos prevalecían por sobre la normas jurídicas positivas que dimanan de los órganos estatales competentes. En consecuencia, el derecho positivo sería entendido como una instancia meramente declarativa o reconocedora — de ningún modo creadora- de derechos preexistentes al Estado. Con otras palabras, los órganos estatales creadores del normas jurídicas de alcance general — principalmente el poder legislativo- no hacían más que reconocer derechos de las personas que precedian a la institución misma del gobierno del Estado.

\section{A MODO DE CONCLUSIÓN}

La CSJN apela a un peculiar concepto de derecho natural para justificar la inconstitucionalidad de las leyes que decretaban el perdón de crímenes de lesa humanidad cometidos en la última dictadura cívico-militar de Argentina en el caso "Simón". Ese concepto de derecho natural asume que el fundamento de obediencia al derecho positivo no se apoya en una norma que integra el ordenamiento jurídicopositivo. Por tanto, la Corte argentina caracteriza al deber de obediencia al derecho desde coordenadas transpositivistas. Más aún, la caracterización que se hace de ese deber resulta compatible con la tradición iusnaturalista. Esto no pretende respaldar que necesariamente habria que recurrir a la noción de derecho natural para justificar la declaración de inconstitucionalidad de las leyes que declararon la amnistía de crimenes de lesa humanidad. Lo que sí se ha pretendido poner de relieve a lo largo de este trabajo es que la argumentación que desplegó la Corte Suprema descansaba sobre una premisa iusfilosófica que no resulta compatible con el positivismo jurídico.

\section{BiBLIOGRAFÍA}

AA.VV., La injusticia extrema no es derecho (De Radbruch a Alexy), R. L. VIGo (ed.), Buenos Aires, Eudeba, 2004.

Bakker, Christine A. E., "Full Stop to Amnesty in Argentina: the Simón Case", en Journal of International Criminal Justice 3 (2005), pp. 1106-1120.

BAdenI, Gregorio, "El caso 'Simón' y la supremacía constitucional”, en La Ley 2005-D, 639.

BobBio, Norberto, El problema del positivismojurídico, 5 edición, México D. F., Fontamara, trad. E. Garzón Valdés, 1997.

41 Cfr. "Simón”, voto de Maqueda, consid. 37, párrafo 1. 
EL DERECHO NATURAL Y LA INCONSTITUCIONALIDAD DE LOS DELITOS DE LESA HUMANIDAD...

Corte Suprema de Justicia de la Nación Argentina (2005), “Simón, Julio H. y otros s/ privación ilegítima de la libertad”, Fallos: 328:2056.

FinNis, John, Natural Law and Natural Rights, 2 edición, Oxford, Oxford University Press, 2011.

Hart, H. L. A., The Concept of Law, 2 edición, Oxford, Clarendon Press, 1994.

Kelsen, Hans, "The Pure Theory of Law: its Method and Fundamental Concepts", en The Law Quarterly Review 50 (1934), pp. 474-498.

Kelsen, Hans, "What is the Pure Theory of Law?", Tulane Law Review 34 (1960), pp. 269-276.

Kelsen, Hans, "On the Basis of Legal Validity", en American Journal of Jurisprudence 26 (1981), pp. 178-189.

LEGARRE, Santiago, "Crimes against Humanity, Reasonableness and the Law: the Simon Case in the Supreme Court of Argentina”, en Chinese Journal of International Law 5/2 (2006), pp. 723-732.

Magnavacca, Silvia, Léxico técnico de filosofia medieval, Buenos Aires, Miño y Dávila, 2005.

Massini Correas, Carlos Ignacio y García-Huidobro, Joaquín, "Valoración e inclusión en el Derecho. La máxima "Lex injusta non est lex" y la iusfilosofia contemporánea”, en Juan CIANCIARDO y et al., Razón jurídica moral: estudios sobre la valoración ética en el derecho, México D. F., Porrúa, 2011, pp. 117-145.

Massini Correas, Carlos Ignacio, Constructivismo ético y justicia procedimental en John Rawls, México D.F., UNAM, 2004.

QuintanA, Eduardo Martín, Notas sobre el derecho en el iusnaturalismo, Buenos Aires, EDUCA, 2008.

Rabbi-Baldi Cabanillas, Renato, Teoría del derecho, 3 edición, Abaco, Buenos Aires, 2013.

RabBi-Baldi Cabanillas, Renato, "La causa 'Simón' de la Corte Suprema argentina. Un análisis desde la filosofia del derecho", en AA. VV., Delitos de lesa humanidad. Reflexiones acerca de la jurisprudencia de la CSJN, Buenos Aires, Ediar, 2009, pp. 101-114.

SERna, Pedro, "Sobre las respuestas al positivismo jurídico", Persona y Derecho 37 (1997) 279-314.

SERna, Pedro, Filosofia del derecho y paradigmas epistemológicos: de la crisis del positivismo a las teorías de la argumentación jurídicas y sus problemas, México D. F., Porrúa, 2006. 
Tomás de Aguino, Suma Teológica, I-II (se cita por la edición dirigida por los Regentes de Estudios de las Provincias Dominicanas en España, Madrid, BAC, 1989).

Vargas Guillén, Guillermo, "Prologo", en Giovanni Reale y Darío Antíseri, Historia de la Filosofia I: Filosofia Pagana Antigua, Bogotá, Sociedad San Pablo, trad. J. Gómez, 2007.

VIGo, Rodolfo L., "Consideraciones iusfilosóficas sobre la sentencia en la causa 'Simón’”, La Ley 2005-D, 1245. 